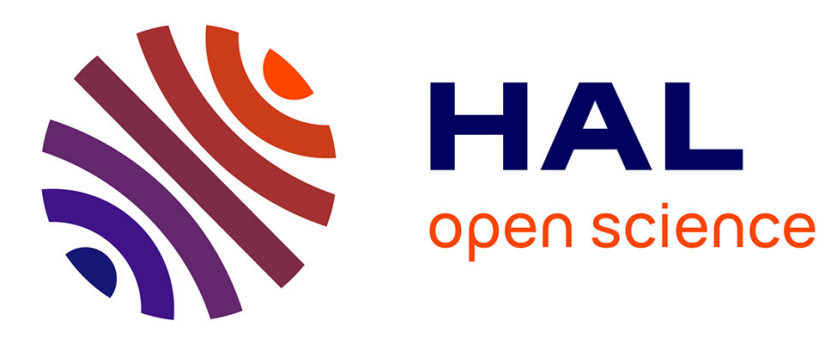

\title{
High Speed Tensile Testing
}

I. Hove, B. Andersson, T. Johnsen

\section{To cite this version:}

I. Hove, B. Andersson, T. Johnsen. High Speed Tensile Testing. Journal de Physique IV Proceedings, 1997, 07 (C3), pp.C3-229-C3-234. 10.1051/jp4:1997341 . jpa-00255498

\section{HAL Id: jpa-00255498 https://hal.science/jpa-00255498}

Submitted on 1 Jan 1997

HAL is a multi-disciplinary open access archive for the deposit and dissemination of scientific research documents, whether they are published or not. The documents may come from teaching and research institutions in France or abroad, or from public or private research centers.
L'archive ouverte pluridisciplinaire HAL, est destinée au dépôt et à la diffusion de documents scientifiques de niveau recherche, publiés ou non, émanant des établissements d'enseignement et de recherche français ou étrangers, des laboratoires publics ou privés. 


\title{
High Speed Tensile Testing
}

\author{
I.H. Hove, B. Andersson and T.E. Johnsen \\ Forskingsveien 1, Dept of Casting and Metal Forming, SINTEF, P.O. Box 124 Blindern, 0314 Oslo, \\ Norvège
}

\begin{abstract}
The experimental method of the testing at a high speed machine with ram speed of $1-10 \mathrm{~m} / \mathrm{s}$ is described. The reproducibility and the effects of the material and the ram speed on the oscillations in measured load have been studied. A software for subtracting the oscillations, which seem to come mainly from the load measurements system, from the recorded load signal to get the material response has been developed. By our method the time from a sample is mounted to the results from the test is ready is about $20 \mathrm{~min}$.
\end{abstract}

Aluminium (3005) and steel have been tested both at high speed and at conventional speed. The mechanical properties as function of strain rate are found.

Résumé : Cet article décrit la méthode expérimentale utilisée pour un test sur une machine de traction à grande vitesse dont la vitesse ram est de $1-10 \mathrm{~m} / \mathrm{s}$. La reproductibilité. les effets dus au matériau et à la vitesse ram sur les oscillations sous contrainte ont été étudies. Un programme a été développé pour soustraire du signal de contrainte enregistré les oscillations provenant principalement du système de mesure sous contrainte afin d'obtenir la réponse du matériau. A l'aide de cette méthode. le temps utilisé entre la mise en place de l’échantillon et les résultats du test se réduit à 20 min.

\section{INTRODUCTION}

Forming of metals (for example rolling, extrusion, drawing and stretching) is an important part of the industry in Norway. Mathematical models have been developed to simulate different forming operations. The models need material data such as stress/strain relationships as input. Tensile testing at low strain rates (up to $500 \mathrm{~mm} / \mathrm{min}$ i.e. quasistatic conditions) is a common method to find such data. A problem arises because most material data depend on the strain rate and the strain rate during the forming process is much higher than the rate obtained in conventional tensile testing machines. Other methods must then be used to find the material data for the actual deformation rate.

Testing at high strain rate has been conducted for several decades. The Split Hopkinsen bar in different modifications are well known high rate testing methods [1-5]. In the resent years, tensile machines which are able to test at medium rates $(1-20 \mathrm{~m} / \mathrm{s})$ have come into the marked. Yet, very little has been published from testing with these machines [6].

SINTEF Materials Technology has installed one of these new machines, type Schenck Hydropuls VHS100/10. The ram speed during the test can be varied between $1-10 \mathrm{~m} / \mathrm{s}$, which corresponds to $\varepsilon=2-1000 \mathrm{~s}^{-1}$ (depending on the length of the deforming zone). The high speed testing machine covers most of the actual rates for different forming operations. Testing at high rate will also be of interest for people working with damage analyses, impact testing etc. In addition to find the stress/srain curves, it is also important to study the micro structure, as deformed and as recrystallised, in samples deformed at high strain rates. 
In the high speed tensile machine the load is measured by a piezo electric crystal. During testing the crystal, the system and the sample will oscillate. The oscillations will superimpose the load signal.

SINTEF wanted to get a better understanding of these oscillations. The reproducibility in the oscillations and the effect of deformation rate and material (aluminium and steel) on the oscillation have been studied. In addition some tests have been conducted to investigate if the oscillations in the measured load is present in the sample. Version 1 of a software program which calculates the material response from the load, displacement and time raw data has also been developed.

\section{EXPERIMENTAL}

A Schenck Hydropuls VHS 100/10 testing machine has been used. The capacity of the machine is 100 $\mathbf{k N}$ and the ram speed can be varied between $1-10 \mathrm{~m} / \mathrm{s}$. The load is measured by a piezo electric crystal. The displacement is measured by detecting the movement of the lower cylinder. The raw data (time, load and displacement) are recorded by an ADAM transient recorder and afterwards transmitted to a PC. The sampling frequency is typically $2-16 \mu$ s, depending on the test rate and the elongation of the sample.

Two different materials are used: aluminium (3005) and steel. Table 2 and 3 show the chemical composition of the materials.

Table 1: Chemical composition of aluminium (3005), wt \%.

\begin{tabular}{|l|l|l|l|l|l|l|l|l|}
\hline Alloy & $\mathbf{S i}$ & $\mathbf{F e}$ & $\mathbf{C u}$ & $\mathbf{M n}$ & $\mathbf{M g}$ & $\mathbf{C r}$ & $\mathbf{Z n}$ & $\mathbf{T i}$ \\
\hline 3005 & 0.455 & 0.662 & 0.180 & 1.032 & 0.414 & 0.043 & 0.206 & 0.023 \\
\hline
\end{tabular}

Table 2: Chemical composition of the steel material, wt\%.

\begin{tabular}{|l|l|l|l|l|l|l|l|l|l|l|l|l|}
\hline $\mathbf{C}$ & $\mathbf{S i}$ & $\mathbf{M n}$ & $\mathbf{P}$ & $\mathbf{S}$ & $\mathbf{C r}$ & $\mathbf{N i}$ & $\mathbf{M o}$ & $\mathbf{V}$ & $\mathbf{C u}$ & $\mathbf{A l}$ & $\mathbf{N b}$ & $\mathbf{B}$ \\
\hline 0.13 & 0.30 & 1.25 & 0.010 & 0.002 & 0.10 & 0.04 & 0.197 & 0.01 & 0.01 & 0.05 & 0.026 & 0.02 \\
\hline
\end{tabular}

3005 was rolled sheet ( $2 \mathrm{~mm}$ thickness) in a $\mathrm{H} 69$ condition (back annealed to $\mathrm{H} 28$ and temper rolled with $10 \%$ reduction). The steel samples were made out of a Weldox $700 \mathrm{E}$ plate. The geometry of the samples are in accordance to ASTM E8M, but one end is elongated.

The materiais have been tested at 3 rates, 1,5 and $10 \mathrm{~m} / \mathrm{s}$ at the high speed machine and at 1,10 and $100 \mathrm{~mm} / \mathrm{min}$ at a conventional machine. For some of the samples tested at $\mathrm{v}=1 \mathrm{~m} / \mathrm{s}$, a strain gauge was placed in the head on the sample.

\section{RESULTS}

The load/time curves for 3005 and steel for 1,5 and $10 \mathrm{~m} / \mathrm{s}$ are shown in figure $1-2$. The typical frequencies in different material at different rates are given in table 3.

The load/time curves for 3 parallel samples of 3005 tested at $v=10 \mathrm{~m} / \mathrm{s}$ are given in figure 3 .

Results from strain gauge experiments are shown in figure 4 .

Ultimate tensile stress and total elongation as function of deformation rate are given in figure 5 and 6 for aluminium and steel.

Table 3: Typical frequencies in different materials and different rates.

\begin{tabular}{|l|l|l|}
\hline Deformation rate & Aluminium, 3005 & Steel \\
\hline $1 \mathrm{~m} / \mathrm{s}$ & $1 \mathrm{kHz}, 6 \mathrm{kHz}$ and $20 \mathrm{kHz}$ & $6-7 \mathrm{kHz}$ \\
\hline $5 \mathrm{~m} / \mathrm{s}$ & $1 \mathrm{kHz}, 6 \mathrm{kHz}$ and $20 \mathrm{kHz}$ & $6-7 \mathrm{kHz}, 1 \mathrm{kHz}$ and $35-40 \mathrm{kHz}$ \\
\hline $10 \mathrm{~m} / \mathrm{s}$ & $6 \mathrm{kHz}$ & $6-7 \mathrm{kHz}$ \\
\hline
\end{tabular}




\section{DISCUSSION}

\subsection{Oscillations in load/time curves}

The load/time curves have oscillations and parallel samples show good reproducibility, figure 3 . This shows that the oscillations are not accidental noise but have a consistent physical explanation.

In aluminium three typical frequencies are found: $20 \mathrm{kHz}, 6 \mathrm{kHz}$ and $1 \mathrm{kHz}$, table 3 . The amplitude of the different frequencies can vary from sample to sample. At $10 \mathrm{~m} / \mathrm{s}$ only $6 \mathrm{kHz}$ is observed. The duration time of the test is too short to find $1 \mathrm{kHz}$, but why $20 \mathrm{kHz}$ is not observed is not clear. The oscillations for aluminium tested at $v=10 \mathrm{~m} / \mathrm{s}$, shown in figure 1 and 3 , seem to be a result of two damped and couple sinus waves.

In steel a frequency of $6-7 \mathrm{kHz}$ is found at all three rates. At $5 \mathrm{~m} / \mathrm{s}$ also $35-40 \mathrm{kHz}$ and $1 \mathrm{kHz}$ are observed.

If we assume that the oscillations are caused by elastic waves, the frequencies depend on the wave speed given by equation (1). As (1) shows the wave speed and the frequency are independent of the rate. This is the reason why the same frequencies occur at different rates. The amplitude is however depending on the deformation rate, equation (2), as observed in figure 1-2.

$$
\mathrm{c}=(\mathrm{E} / \rho)^{1 / 2}
$$

$\Delta \sigma=\rho c \Delta v$

$E=$ Elastic-modulus, $\rho=$ density, $c=$ elastic wave speed, $\Delta v=$ rate change

\subsection{Oscillations in the load measurement system and the sample}

The oscillations in the load/time curves can be caused by the load measurement system or can be real oscillations from the sample. Experiments with a strain gauge at the head of the samples were conducted to investigate if the samples experience the same oscillations as observed in the measured load. Both the signal from the piezo electric crystal and the signal from the strain gauge were recorded by a transient recorder. The two signals as function of time are shown in figures $4 a$ ) for aluminium and $4 \mathrm{~b}$ ) for steel. The oscillations in the two signals are quit different. The samples experience nearly no oscillations, so it seems that the oscillations in the measured load are mainly from the load measurement system. The oscillations in the load measurement system will superimpose the material response. There are two main approaches that can be followed to find the material response:

1. Do so good instrumentation that logged data can be used to calculate stress, strain and temperature directly.

2. Use simple measurements of ram speed, displacements, load and temperature but through an investment of the understanding of artifacts, systematic errors and the physics of non material effect, seperate out the true material response

The first is very time consuming both in establishing the system and in each experiment. The last requires a lot of work to be sure about the true response, but then it is very efficient. It has been shown that the results is on the same level at a fraction of the cost, for the last compared to the first [7].

\subsection{Calculation program}

From the Schenck machine the force and displacement as function of time are recorded. SINTEF Materials Technology has developed a Windows based software to calculate the stress/strain curve from the raw data. The calculation can be divided in 6 steps:

1. Calculation of trial strain and stress from the load, displacement and time raw data.

2. Curve fit of the stress/strain curve based on Voce equation:

$$
\sigma=\sigma_{\infty}-\left(\sigma_{\infty}-\sigma_{0}\right) e^{-\left(\varepsilon / \varepsilon_{r}\right)}
$$

3. Subtract the fitted curve from the stress-strain curve in 1 to get the trial oscillation part of the curve.

4. Fourier analysis of the oscillations 
5. Material response $=$ trial stress/strain curve - true oscillations part defined by the fourier series leaving out the first two terms.

6. Make a new curve fit to find the material response

An example of the result from the calculation software is shown in figure 7 . The Voce equation is chosen for the curve fit because the stress/strain curves for aluminium alloys usually follows a Voce equation Steel does not follow Voce, so another material law must then be used. The software is made in such a way that it is easy to change the material law used in step 2 and 6.

The curvature of the stress/strain curve is sensitive to the choice of zero point, so care must be taken so that the initial yield stress can be found correctly. Values as ultimate tensile strength and total elongation is however easy to find.

From the study of the oscillations, it was found that typical frequencies are observed. In the next version of the calculation program these typical frequencies will be subtracted from the load/time curve and then a curve fit will be done.

With the described testing method and calculation program the time span from a sample is mounted to the results are calculated is about $20 \mathrm{~min}$.

\subsection{Mechanical properties as function of deformation rate}

For aluminium it was observed that the stress was nearly independent of the strain rate, while the elongation was doubled from low to high rates, figure 5. This is an important observation. In for example sheet forming, the total elongation is usually correlated to the formability. The deformation rate in most forming operations is much higher than what can be obtained in conventional testing machines. If the elongation found by testing at a conventional machine is used, it gives an unrealistic low value for the formability at high deformation rate. The result from 3005 demonstrates the necessity for testing materials at the actual deformation rate.

Steel has a slight increase in strength with increasing deformation rate. The elongation is low for the lowest rate and reach a level for higher rates.

\section{CONCLUSION}

- Parallel samples show a very good reproducibility in the load/time curves.

- The frequencies of the oscillations in the load signal, are independent of the deformation rate, but the amplitudes increase with increasing deformation rate. There are common frequencies in aluminium and steel.

- The oscillations in the load signal are mainly from the load measurement system and not present in the sample.

- The method which describes the oscillations mathematically and subtract them from the total load to get the real material response, is an easy and effective method which gives satisfaying results.

\section{REFERENCES}

1. Zukas, Nickolas, Swift and Curran, Impact dynamics, John Wiley \& Sons, 1982.

2. H. Kolsky, Proc. Phys Soc, B, 62, 672, 1949.

3. U.S. Lindholm, J. Mech. Phys Solids, 12, 317, 1964.

4. W-S Lee and H-F Lam, J. of Matr. Proc. Tech, 57 (1996), 233-240.

5. K. Ogawa, Inter. J. of Plasticity, vol1, p 347-358, 1985.

6. B. Andersson and S. R. Skjervold, Aluminium alloys part 4, ICAA5, Grenoble, 1996.

7. I. Hove, B. Andersson and T.E. Johnsen, Tensile testing at high strain rates at Schenck Hydropuls

VHS100/10, SINTEF report STF24 F97008, March 1997 
Figure 1: Load as function of displacement for 3005 tested at different rates.
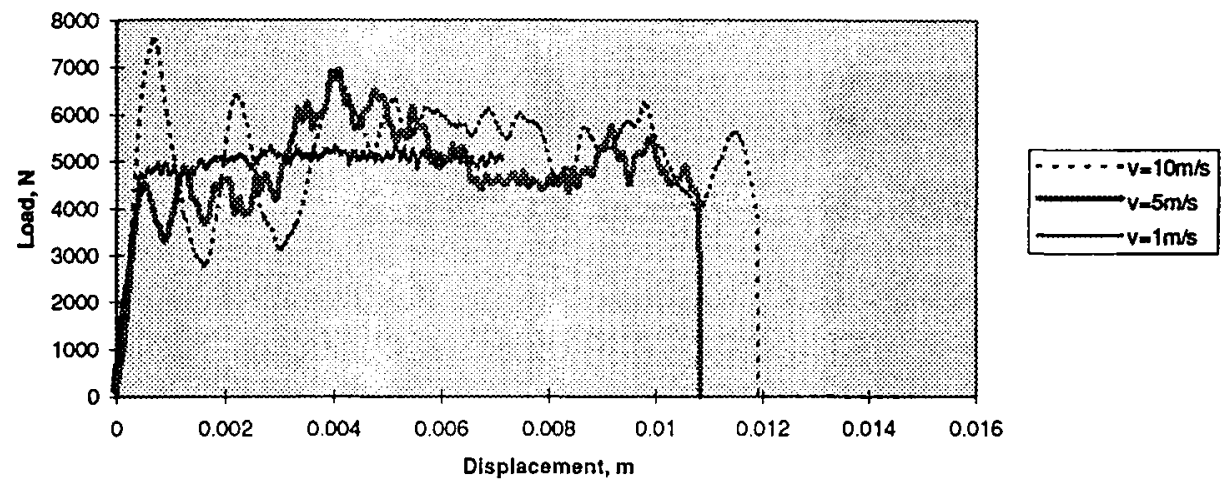

Figure 2: Load as function of displacement for steel tested at different rates
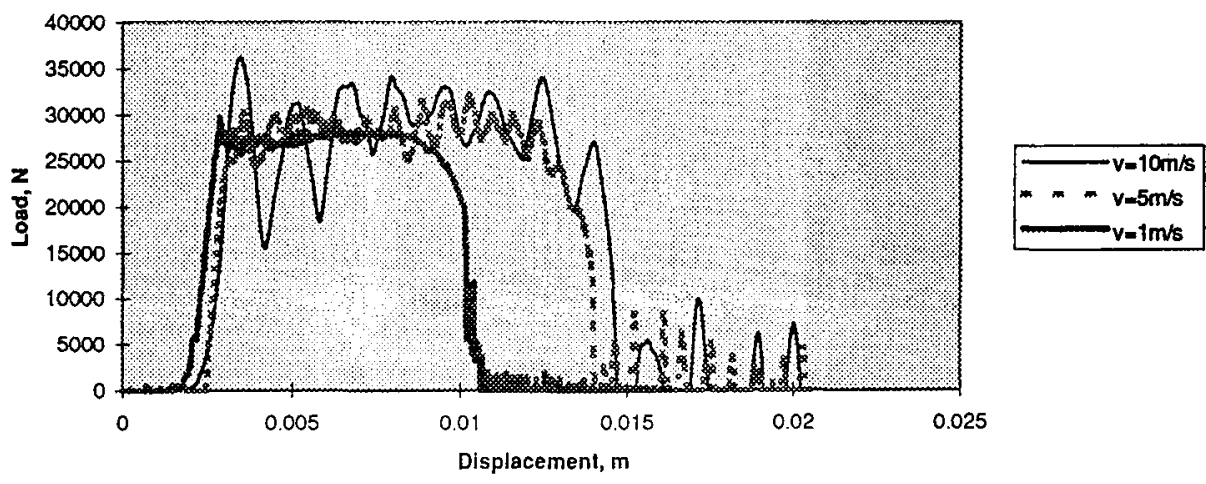

Figure 3: Load/time curves for 3005 tested at $v=10 \mathrm{~m} / \mathrm{s}$
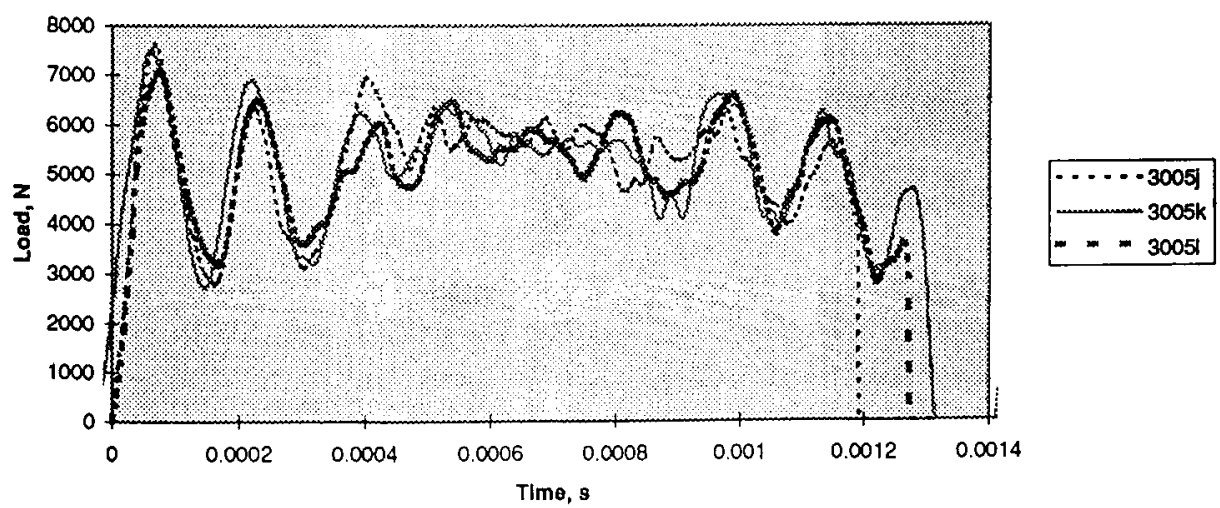


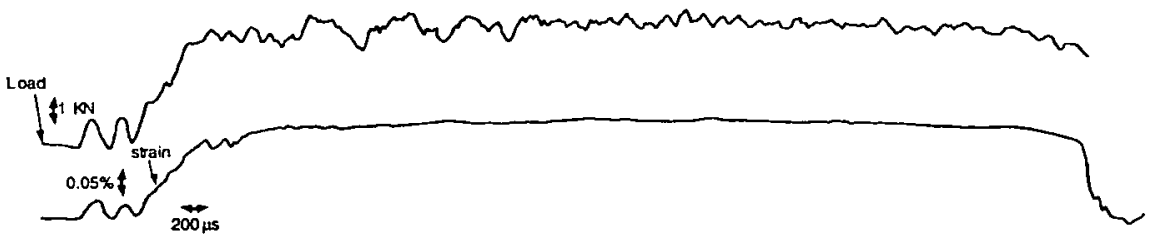

Figure 4a: Load/time and strain/time curves for aluminium, 3005

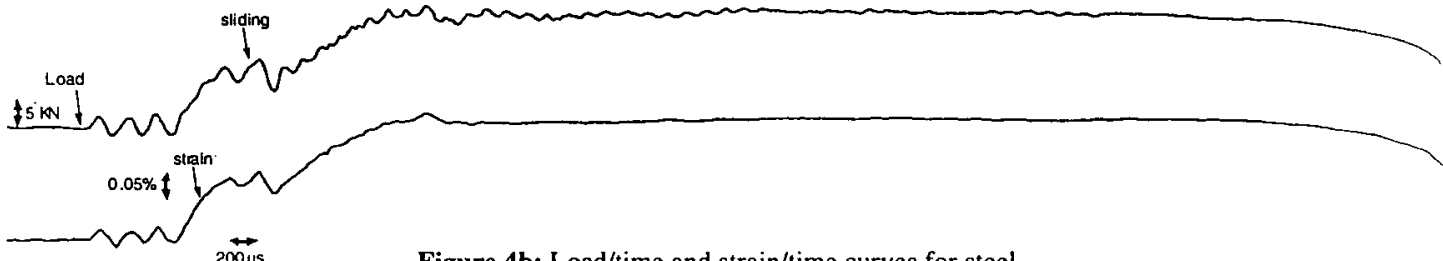

Figure 4b: Load/time and strain/time curves for steel

Figure 5: Mechanical properties of 3005 as function of rate.

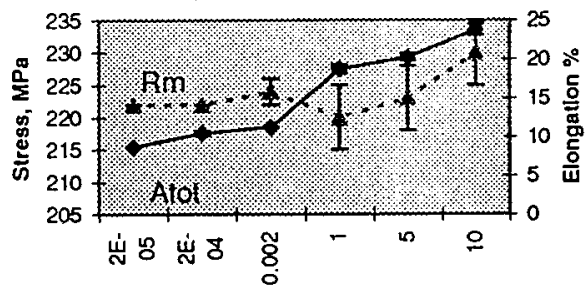

Deformation rate, $\mathrm{m} / \mathrm{s}$
Figure 6: Mechanical properties of steel as function of rate.

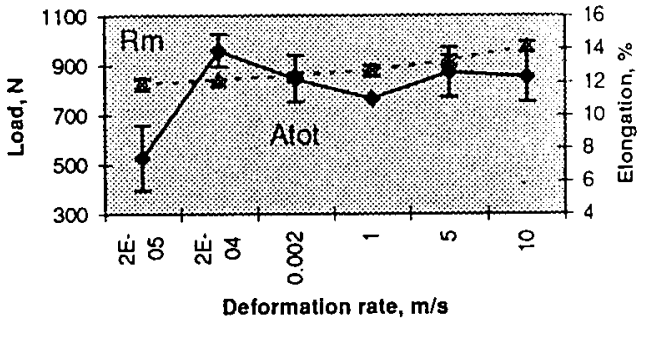

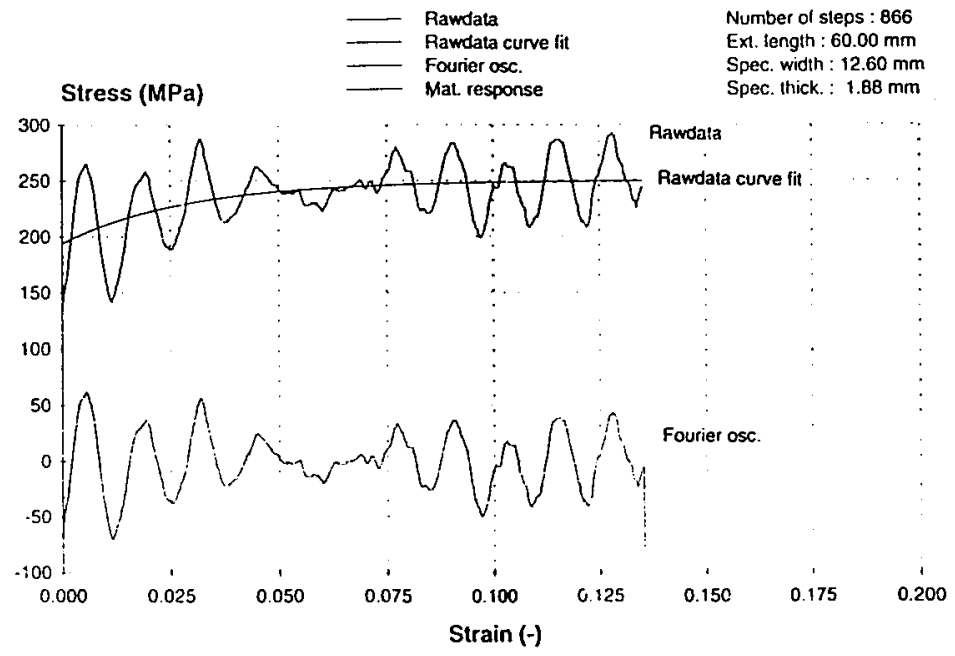

Figure 7: Output from the calculation program. Aluminium (3005) tested at $v=5 \mathrm{~m} / \mathrm{s}$.

In this case the raw data curve fit curve and the material response curve are the same. 